\title{
Asparagus racemosus extract increases the life span in Drosophi la melanogaster
}

\author{
K. V. Kiran Kumar ${ }^{*}$, K. S. Prasanna ${ }^{2}$, J. S. Ashadevi ${ }^{1}$ \\ ${ }^{1}$ Genetics Research Laboratory, Department of Zoology, Yuvaraja's College, University of Mysore, Mysore, India. \\ ${ }^{2}$ Postgraduate Department of Applied Zoology, Maharani's Science College for Women, J.L.B. Road, Mysore, India.
}

\author{
ARTICLE INFO \\ Article history: \\ Received on: $31 / 07 / 2015$ \\ Revised on: 11/08/2015 \\ Accepted on: 20/08/2015 \\ Available online: $24 / 08 / 2015$ \\ Key words: Asparagus \\ racemosus, antioxidants, \\ longevity, oxidative stress, \\ Acrylamide, $\mathrm{G}_{6} \mathrm{PD}$, Drosphila \\ melanogaster.
}

\begin{abstract}
Free radicals and oxidative stress are recognized as important factors in the biology of aging as well as in many age-related diseases. Dietary antioxidant plays a potential role in the reduction of age-related diseases. Many medicinal plants are rich source of antioxidants and promote longevity. Drosophila is a suitable animal model to study ageing and oxidative study. This study evaluated the antioxidant property of Asparagus racemosus on longevity and $\mathrm{G}_{6} \mathrm{PD}$ activity in Drosophila melanogaster. The analyses were carried out in stress and non stress conditions. Longevity increased almost by $29 \%$ at low concentration and $41 \%$ at high concentration in extract supplemented flies. $\mathrm{G}_{6} \mathrm{PD}$ level was significantly increased in extract supplemented larval stages than adults. The antioxidant property of Asparagus racemosus increases the larval $\mathrm{G}_{6} \mathrm{PD}$ activity thus; it extends the lifespan in adults.
\end{abstract}

Abbreviation A. racemosus Asparagus racemosus, ACR Acrylamide, OS Oxidative stress, G 6 PD Glucose 6 Phosphate Dehydrogenase.

\section{INTRODUCTION}

Ageing is a slow process characterized by progression at cellular, tissue and organ level during the fag end of an organism's life. It results in gradual functional decline and decrease the adaptability of an organism. Free radicals play an important role in ageing and age-associated diseases [1, 2]. Free radicals are neutralized by an antioxidant defense system. Reducing oxidative damage is one of the promising interventions to some extent in delay the progression of ageing and age-related diseases.

The process of ageing takes place simultaneously in all systems of body and thus makes it unsuitable for vitro studies. The comparative study of ageing in model organism holds the potential to reveal information about the ageing process in humans [3]. Hence, many principal animal model systems are being used to investigate the ageing process like, nematode $C$. elegans, fruit fly - Drosophila melanogaster, and the mouse or rat. All these animals have some limitations for studies on ageing but, Drosophila has proved to be cost effective and a fast model system in drug research. Because of short life span, ease in culture, well established developmental events, large number of mutations and less genomic size [4], Drosophila is considered as

* Corresponding Author

Email: ashajs2000@gmail.com one of the test model to study ageing and related aspects.

Antioxidant system works against the reactive oxygen species (ROS) in human cell. The supplementation of antioxidants through diet changes the balance between oxidants and antioxidants, should increases longevity [5]. Many plants are the source of natural antioxidants [6]. The effect of Rosa damascene and Rhodiola on lifespan and other fitness parameters has been studied in D. melanogaster [7]. The anti-ageing activity of blueberry was reported in D. melanogaster through life span experiments [8].

Effects of aqueous and ethanolic extracts of Stachyslavan dulifolia has been studied on the longevity of D. melanogaster [9]. Similarly, lifespan studies have been made in D. melanogaster using different extracts of many herbal plants namely Emblica officinalis, Curcuma longa, Triticum aestivum, Aloe vera [1014].The supplementation of cocoa extends the life span of $D$. melanogaster under different oxidative stress conditions [15].

Natural antioxidants having high flavonoids and phenolic compounds prevent the free radical damage to tissues and enhance longevity. The plant Asparagus racemosus is one such medicinal plant having high antioxidant property, chosen for the present study to investigate the effect on ageing. A. racemosus is commonly known as Shatavari, belongs to the family Liliaceae which is one of the most important herbs in Ayurvedic medicine, dealing with problems connected women's fertility, reducing menopausal 
symptoms, promoting rejuvenation, mental and physical health [16-17]. It is used to treat conditions such as nervous disorders, dyspepsia, tumors, inflammation, hyperdipsia, neuropathy and hepatopathy [18].

The potent antioxidant property of $A$. rasemosus has been reported in different solvent extracts and reported that methanolic extract of $A$. racemosus has moderate free radical scavenging action [19-21]. In Ayurveda it is believed that Shatavari improves defense mechanisms of the body and enhances longevity. However, the effect of $A$. racemosus on life span of $D$. melanogaster has not been studied so far. As A. racemosus is considered as an important herbal plant in Ayurveda, the present study is carried out to find out the longevity and enzyme studies in extract supplemented flies of $D$. melanogaster.

\section{MATERIALS AND METHODS}

\subsection{Chemicals}

Ascorbic acid, 1, 1 diphenyl-1-2 picryl hydrazyl (DPPH), Gallic acid, Folin-Ciocalteu reagent, Acrylamide, NADP, Quercetin, D-glucose 6 phosphate were obtained from SRL, Pvt. Ltd, India. Tannic acid was obtained from RANKEM Pvt. India.

\subsection{Culturing of Drosophila}

Drosophila melanogaster, wild stocks of strain Oregan K were obtained from Drosophila Stock Center, Department of Zoology, Manasagangothri, University of Mysore, Mysore, Karnataka. The flies were cultured in a standard wheat cream agar media seeded with yeast granules and maintained at $22 \pm 1^{\circ} \mathrm{C}$ of relative humidity $70-80 \%$. For all the experiments synchronized flies were used from isofemale line stocks.

\subsection{Preparation of plant extracts}

The roots of $A$. racemosus plant was collected in Mysore district, Karnataka, India, washed then dried in the laboratory under shade at room temperature and powdered using an electric blender. The powder was subjected to ethanolic extraction by using Soxhlet extraction unit and dried, thus obtained extracts were used as additional supplementation for all the experiments.

\subsection{IN VITRO ANALYSIS}

\subsubsection{Phytochemical analysis of $A$. racemosus}

The ethanolic extract of $A$. racemosus was subjected to phytochemical analysis to quantify the antioxidants such as total contents, reducing power activity, phenolics, flavonoids and tannins. All the in vitro studies of $A$. racemosus were made of concentration $5 \mathrm{mg} / \mathrm{ml}$ and the quantities were measured using UVVis Spectrophotometer (ELICO Ltd. India).

\subsubsection{DPPH Free Radical Scavenging Assay}

The total antioxidant activity was measured by DPPH free radical scavenging method as per standard method [22] with slight modification. Methanol was used as control and Quercetin was used as standards $(1 \mathrm{mg} / \mathrm{ml})$. The mixture of extract and DPPH was shaken vigorously and kept in the dark for $30 \mathrm{~min}$. The absorbance of the resulting solution was measured at $517 \mathrm{~nm}$. The scavenging activity of each extract on DPPH radical was calculated using the following equation

$$
\text { Scavenging activity }(\%)=\frac{(1-\text { Absorbance of sample })}{\text { Absorbance of control }} \times 10
$$

\subsubsection{Reducing power assay}

Reducing power assay of $A$. racemosus extract was carried out by potassium ferricyanide method [23]. $1 \mathrm{ml}$ of plant extract solvent was mixed with $2.5 \mathrm{ml}$ phosphate buffer $(0.2 \mathrm{M}$, $\mathrm{pH}$ 6.6) and $2.5 \mathrm{ml}$ of potassium ferricyanide. The mixture was then incubated in water bath at $50^{\circ} \mathrm{C}$ for 20 minutes. To this mixture $2.5 \mathrm{ml}$ of trichloroacetic acid was added. It was then centrifuged at $3000 \mathrm{rpm}$ for 30 minutes. Finally $2.5 \mathrm{ml}$ of the supernatant was mixed with equal amount of distilled water and $0.5 \mathrm{ml}$ of ferric chloride. Ascorbic acid $(1 \mathrm{mg} / \mathrm{ml})$ was used as standard and then absorbance was measured at $700 \mathrm{~nm}$.

\subsubsection{Estimation of Phenolics}

The total phenolic content in the ethanolic extract in A. racemosus was determined by Folin-Ciocalteu reagent method [24]. $0.5 \mathrm{ml}$ of plant extract was mixed with $2.5 \mathrm{ml}$ of FolinCiocalteu reagent. Mixture was incubated for 15 minutes at $45^{\circ} \mathrm{C}$ after adding $2 \mathrm{ml}$ of $7.5 \%$ sodium carbonate. Then the absorbance was measured at $765 \mathrm{~nm}$ with Gallic acid as standard.

\subsubsection{Determination of total flavonoids}

Determination of flavonoids in A. racemosus was made as per procedure of Wang and Jiao [25]. $1 \mathrm{ml}$ of plant extract was mixed with $3 \mathrm{ml}$ of methanol, $0.2 \mathrm{ml}$ of aluminum chloride and 0.2 $\mathrm{ml}$ of $1 \mathrm{M}$ potassium acetate and $5.6 \mathrm{ml}$ of distilled water. Mixture was incubated for 30 minutes at room temperature. Quercetin was used as standard and the optical density was measured at $415 \mathrm{~nm}$.

\subsubsection{Determination of Tannin}

Tannin estimation in A. racemosus was made as per the standard procedure [26]. For the estimation $0.5 \mathrm{ml}$ of extract was mixed with $0.25 \mathrm{ml}$ of $1 \mathrm{~N}$ Folin-Ciocalteu reagent and $1.25 \mathrm{ml}$ of $20 \%$ sodium carbonate. Mixture was incubated at room temperature for about 40 minutes. Tannic acid was used as standard and the absorbance was measured at $725 \mathrm{~nm}$ against blank.

\subsection{IN VIVO ANALYSIS}

\subsubsection{Treatment protocols}

A preliminary study was made to determine the dose effect of $A$. racemosus on survival of $D$. melanogaster, flies were exposed to different concentrations of extracts, namely $0.1 \%$, $0.5 \%, 0.75 \%$. $1.0 \%$ and $1.5 \%$. Two concentrations viz. $0.1 \%$, and $1.0 \%$, were chosen as optimal concentration for all the experiments.

\subsubsection{Longevity}

Longevity experiments were carried out as per the standard procedure [27]. It was conducted in unmated male and 
female flies. Newly emerged flies were segregated within 4-6 hrs once and 25 flies were released in different groups to each experimental culture vial of size $9 \times 3 \mathrm{~cm}$ which contained extract of A. racemosus (v/v; $10 \mu \mathrm{l} / 3 \mathrm{ml}$ of culture media) along with regular wheat cream agar media. Only yeast seeded groups were considered as control. Once in every 3 days flies were transferred to fresh culture vials. Vials were checked daily and observed for mortality. The date of death was recorded for each fly. Visual inspection of the vials was usually adequate to determine the viability of the flies. 100100 such flies were maintained instead of replicates in both control and extract treated batches. Experiments were carried out in two different concentrations. Individual groups were compared by mean lifespan in days.

\subsubsection{Oxidative stress resistance test (OS test)}

Acrylamide (ACR) has been proved as a good oxidative stress molecule [28]. It has been used to measure resistance against stress in in vivo studies. To detect the resistance ability in $A$. racemosus extract, supplemented flies were exposed to different concentrations of ACR ranging from 10, 20, 30, 40, 50mM and mortality time was observed. $20 \mathrm{mM}$ ACR was fixed for further stress induction analysis. 10 days aged $A$. racemosus extract supplemented flies were starved in empty vials of size $8.5 \times 3 \mathrm{~cm}$ for $2 \mathrm{hrs}$. Then flies were exposed $20 \mathrm{mM}$ ACR in $5 \%$ sucrose solution through a soaked filter paper. For this experiment, 50 flies (10flies/vial) were maintained in each batch. The rate of survival was recorded for every 6hrs. once until all the flies reached mortality in all the batches.

\subsubsection{Glucose -6-Phosphate dehydrogenase $\left(\mathrm{G}_{6} \mathrm{PD}\right)$ assay}

Enzyme assay was carried out in both the sex of $3^{\text {rd }}$ instars larvae, 30 and 45 days old $A$. racemosus supplemented flies. The whole body homogenate was prepared in $0.1 \mathrm{M}$ Phosphate buffer of $\mathrm{pH} 7.0$ and centrifuged at $5000 \mathrm{rpm}$ for 5 minutes and thus collected supernatant was used for measuring the enzyme activity. The total activity of $\mathrm{G}_{6} \mathrm{PD}$ was estimated in extract supplemented flies by following the standard method [29]. $100 \mu \mathrm{l}$ of supernatant was mixed with $0.4 \mathrm{ml}$ of $1.5 \mathrm{M}$ tris HCL $\left(\mathrm{p}^{\mathrm{H}} 7.5\right.$ ) containing $3.8 \times 10^{-4} \mathrm{M}$ NADP, $0.01 \mathrm{ml}$ of $0.3 \mathrm{M} \mathrm{MgCl}_{2}$ and $0.5 \mathrm{ml}$ of $0.03 \mathrm{M}$ D-glucose 6 phosphate. The activity of the reaction mixture was measured at one minute interval for 3 minutes at $340 \mathrm{~nm}$ using UV spectrophotometer. The activity was calculated based on molar extinction coefficient $6.22 \mathrm{mM}^{-1} \mathrm{~cm}^{-1}$. The activity was measured in non stress conditions and stress conditions. The extract supplemented flies were considered as non stress conditioned group and extract with Acrylamide treated flies were considered as stress conditioned groups. Only yeast fed flies were treated as control groups in non stress batch where as yeast with Acrylamide fed flies were treated as control groups in stress batch. The activities were measured in 3 replicates in each group.

\section{Statistical analysis}

Data were expressed as mean $\pm \mathrm{SE}$ for all in vitro antioxidant assays. To know the level of significance among the analyzed groups in longevity, OS test and enzyme activity measurement data were subjected to one way ANOVA analysis individually using SPSS software of version 16.0. To detect the significant levels between control and extract supplemented batched flies with doses, data were further subjected to DMRT. A probability of $\mathrm{P}<$ 0.05 was considered as significant. The male and female longevity of the analyzed groups were measured through survival curve analysis.

\section{RESULT AND DISCUSSION}

\subsection{In vitro analysis of $A$. racemosus}

The data on phytochemical analysis of ethanolic extract of A. racemosus are shown in Table1. Dietary antioxidants play potential roles in the reduction of age-related diseases [30]. In the present study, phytochemical analysis of $A$. racemosus has been undertaken to correlate the antioxidants with longevity of $D$. melanogaster though it has been reported by others using different solvent extracts $[19,31]$. Plant extract contains high levels of phytochemical which promotes the health and prevents or delays age-related diseases $[32,33]$. All the nutriceutical extract of plants are change to have high levels of polyphenols, which possess high antioxidant activities and other health-promoting properties. Phenolic compounds are powerful chain breaking antioxidants in scavenging the radicals [34, 35], the flavonoids and phenolics prevent the damage against free radicals [36]. In the present investigation the results reveal the root of $A$. racemosus contains rich source of phenolics and flavonoids. The phenolics content was $150 \mu \mathrm{g} / \mathrm{ml}$ and flavonoid content was $85 \mu \mathrm{g} / \mathrm{ml}$. The free radical scavenging activity was $27.19 \%$ and the reducing power activity was also found to be more $(415 \mu \mathrm{g} / \mathrm{ml})$ when compared to other activities. The results of the present study reveal that the ethanolic extract of $A$. racemosus has free radical scavenging and reducing power property with more quantity of Phenolics and flavonoids than tannins

Table 1: Phytochemical constituents in ethanolic extract of $A$. racemosus

\begin{tabular}{llllll}
\hline & $\begin{array}{l}\text { Total } \\
\text { antioxida } \\
\text { nts }\end{array}$ & $\begin{array}{l}\text { Phenolics } \\
(\mu \mathrm{g} / \mathrm{ml}) \\
(\mathrm{Mean} \pm \mathrm{SE})\end{array}$ & $\begin{array}{l}\text { Flavonoids } \\
(\mu \mathrm{g} / \mathrm{ml}) \\
(\mathrm{Mean} \pm \mathrm{SE})\end{array}$ & $\begin{array}{l}\text { Tannin } \\
(\mu \mathrm{g} / \mathrm{ml}) \\
(\mathrm{Mean}) \\
\pm \mathrm{SE})\end{array}$ & $\begin{array}{l}\text { Reducing } \\
\text { power assay } \\
(\mu \mathrm{g} / \mathrm{ml}) \\
(\mathrm{Mean} \pm \mathrm{SE})\end{array}$ \\
\hline $\begin{array}{l}\text { Ethanolic } \\
\text { extract }\end{array}$ & $27.19 \%$ & $150 \pm 0.02$ & $85 \pm 0.04$ & $20 \pm 0.01$ & $415 \pm 0.10$
\end{tabular}

\subsection{Longevity}

Supplementation of pharmaceuticals and nutraceutical compounds of many medicinal plants increases longevity due to their high antioxidant properties. Composition of dietary nutrients plays an important role in modulating lifespan [37, 38]. As the signaling pathways of ageing in man and Drosophila are almost similar [39], the study is carried out in D. melanogaster. Many studies have shown that the consumption of antioxidants rich diet promotes lifespan extension in D. melanogaster [40, 41]. The data on longevity of ethanolic extract of $A$. racemosus supplemented groups with the control group is given in Table 2 . The extracts 
were supplemented through larval feeding with two concentrations namely dose - I $(0.1 \%)$ and dose-II $(1.0 \%)$. The life span was significantly increased in both the doses. All the groups were compared with their mean life span values and $\mathrm{LT}_{50}$ values. $\mathrm{LT}_{50}$ is the lethal tolerance time at which $50 \%$ of the flies died. The $\mathrm{LT}_{50}$ value of control group was 54.62 in male and 50.16 in females. The $\mathrm{LT}_{50}$ values were significantly increased in dose $-\mathrm{I}$ and dose -II treatment groups. The last control male fly died in 83 days, female fly died in 84 days. The corresponding mean life span in control group was 65.08 days for males and 61.70 days for females. In A. racemosus supplemented group in dose $-\mathrm{I}$, the last male fly and female fly survived for 106 and 107 days respectively. However, in dose-II treatment, it extended up to 116 days in male, and 117 days in female. The corresponding mean life span in males was 83.70 in dose $-\mathrm{I}$ and 91.90 in dose-II. The corresponding mean life span in females was 76.99 in dose $-\mathrm{I}$ and 87.04 in dose-II groups. The statistical analysis of the data reveal that both the doses of extract supplemented flies in both the sexes shows the significant differences with the control flies $(\mathrm{P}<0.05)$. Figure 1 shows the pattern of survival through survival curve in extract treated and control flies of D. melanogaster. It has been reported that survival rate of flies treated with Rhodiola root extract are increased by 3.5 days in males and 3.2 days in females than control groups (7).
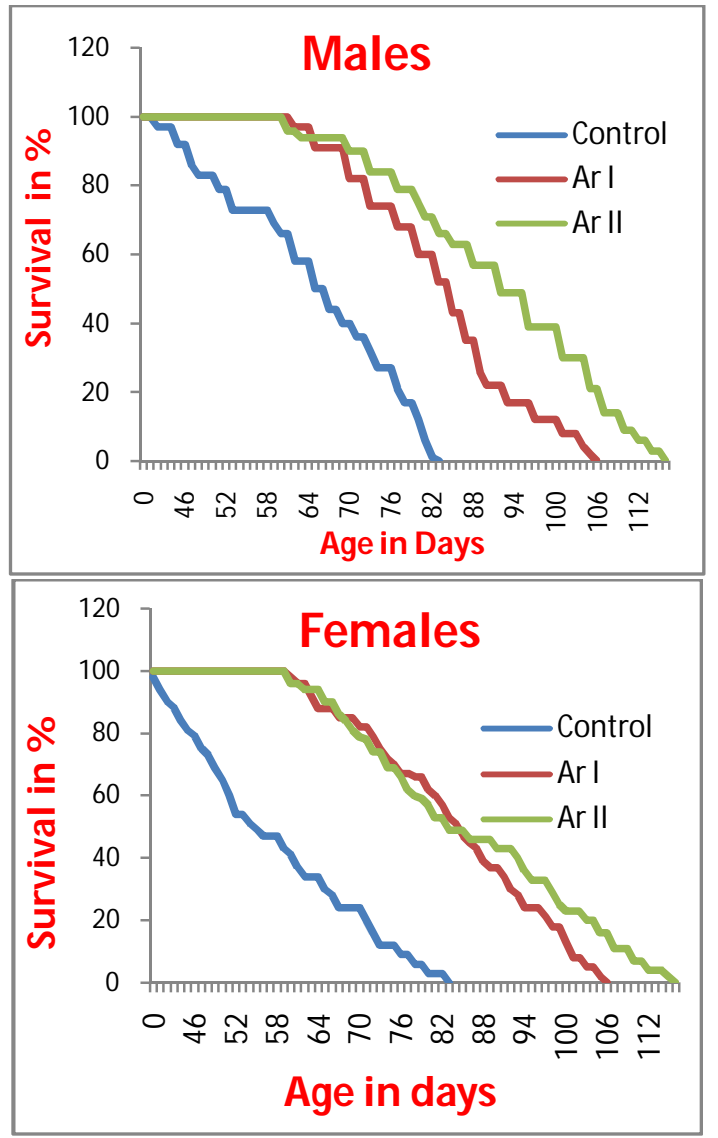

Fig. 1 Survival curves of male and female $D$. melanogaster flies supplemented with $A$. racemosus extract. Ar -I;dose-I treatment batch, Ar-II; dose-II treatment batch .
Further, it has been shown that Acai pulp increases the lifespan by $22 \%$ in female flies [42]. A sex specific lifespan extension has been reported in Cynomorium songaricum extract treated D. melanogaster batches [43]. In the present study, similar such observation is found in A. racemosus extract supplemented batches, where all the males showed increased longevity than females. Further it was observed that dose -II supplemented males have prolonged lifespan than in dose $-\mathrm{I}$ groups. In $D$. melanogaster mating status markedly affected the lifespan where in courtship reduces the longevity of male [44, 45]. Further it has been shown that, mated females have shortened life span than virgin female flies in D. melanogaster due to elevated rate of egg production and increased exposure to males repeatedly [46]. Hence, in the present study, longevity was carried out only in virgin males and females of D. melanogaster

Table 2: Longevity of A. racemosus supplemented flies of D. melanogaster.

\begin{tabular}{lcccccc}
\hline & Male ( Mean \pm SE) & \multicolumn{4}{c}{ Female (Mean \pm SE) } \\
\hline & LT $_{50}$ & $\begin{array}{c}\text { Maximum } \\
\text { days } \\
\text { survived }\end{array}$ & $\begin{array}{c}\text { Mean } \\
\text { lifespan }\end{array}$ & LT $_{50}$ & $\begin{array}{c}\text { Maximu } \\
\text { m days } \\
\text { survived }\end{array}$ & $\begin{array}{c}\text { Mean } \\
\text { lifespan }\end{array}$ \\
\hline Control & $54.62^{\mathrm{a}}$ & 83 & $65.08^{\mathrm{a}}$ & $50.16^{\mathrm{a}}$ & 84 & $61.70^{\mathrm{a}}$ \\
& \pm 1.09 & & \pm 1.23 & \pm 1.21 & & \pm 1.61 \\
I Dose & $74.52^{\mathrm{b}}$ & 106 & $83.70^{\mathrm{b}}$ & $69.56^{\mathrm{b}}$ & 107 & $79.66^{\mathrm{b}}$ \\
& \pm 0.96 & & \pm 1.14 & \pm 1.12 & & \pm 1.71 \\
II Dose & $79.18^{\mathrm{c}}$ & 116 & $91.90^{\mathrm{c}}$ & $76.04^{\mathrm{c}}$ & 117 & $87.04^{\mathrm{c}}$ \\
& \pm 0.31 & & \pm 1.50 & \pm 1.42 & & \pm 1.93 \\
F value & 131.90 & & 110.59 & 126.60 & & 108.63 \\
df & $(2,147)$ & & $(2,297)$ & $(2,147)$ & & $(2,297)$ \\
\hline
\end{tabular}

Note: The strains with the same letter in the parenthesis are not significantly different at $5 \%$ level according to DMRT

The result of longevity in extract treated batches reveals that longevity is dose dependent. The life span increased $28.62 \%$ at low dose treated males while there was $41.21 \%$ increase at high dose treated males. The life span was increased by $29.20 \%$ at low dose treated females and $41.17 \%$ at high dose treated females. This result is in line with the findings of Sun et al. [42]. The results are also similar in treated female batches. The sex wise comparison results revealed the extended life span is more in males than females. The antioxidant property of A. racemosus increases the longevity in D. melanogaster.

\subsection{OS resistance test}

To evaluate the resistance ability of the A. racemosus fed flies under stress conditions, flies were exposed oxidative stress molecule. The result of OS resistance test in males females through supplementation of acrylamide is compiled in Fig.2. The mortality result was almost same in both sexes. The range of mortality in control male and female batches was found to be at 18 hrs to $48 \mathrm{hrs}$. while in dose-I and dose-II, the mortality range was found to be at $18 \mathrm{hrs}$ to $66 \mathrm{hrs}$ and $12 \mathrm{hrs}$ to $72 \mathrm{hrs}$. respectively. The maximum mortality in both the doses was found to be at $42 \mathrm{hrs}$. in male batch. However in female batch, the maximum mortality was at $42 \mathrm{hrs}$. There are strong indications that the level of oxidative stress is elevated during the ageing process. It has been shown that cocoa supplementation on $D$. melanogaster extends the life span 
under oxidative stress conditions [47]. An excess of oxidative stress can lead to the oxidation of lipids and proteins, which is associated with changes in their structure and functions [48]. In the present study the results reveal that there was no sex specific effect in the range of stress induction. The extract supplemented flies were more resistant than control flies under stress condition. Further it was found that the resistance ability was more (72hrs.) at higher dose treatments than lower dose treatment batch (66hrs.). So the antioxidant property of $A$. racemosus is responsible for developing resistance to oxidative stress.

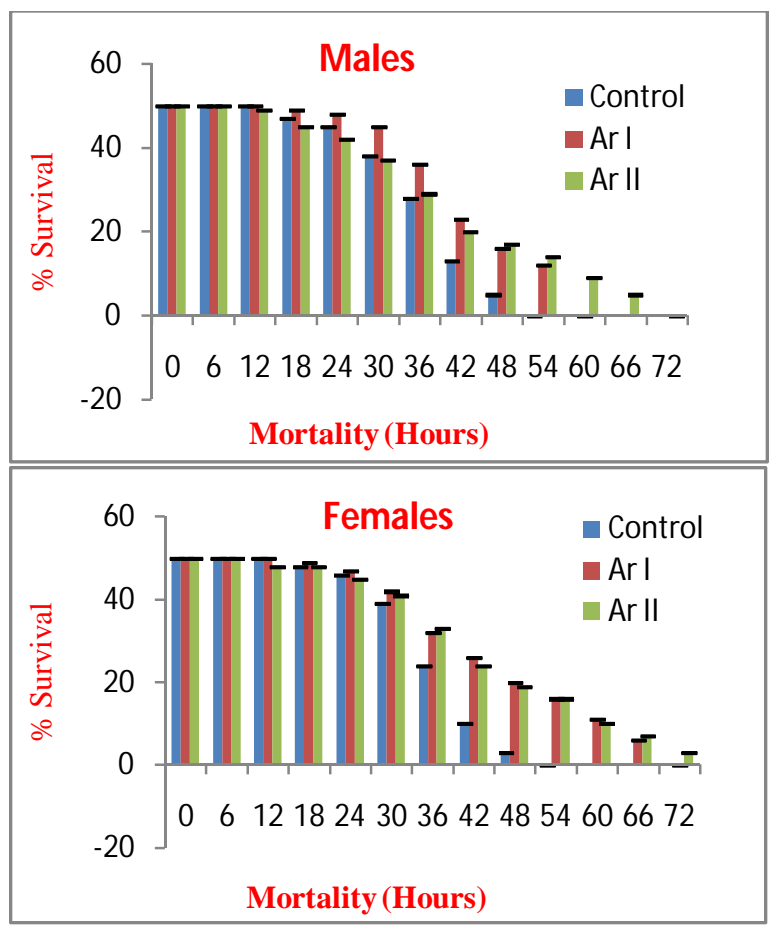

Fig. 2 Survival rate in OS induced flies of male and female D. melanogaster $\mathrm{Ar}$ -I ; dose-I treatment batch, Ar-II; dose-II treatment batch.

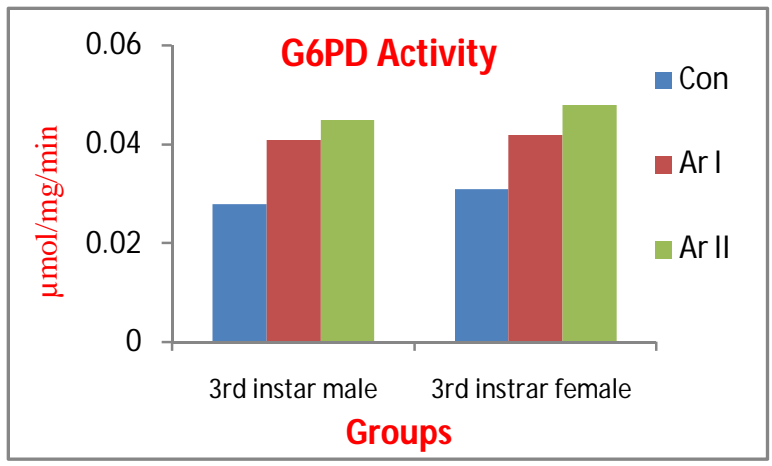

Fig. $3 \mathrm{G}_{6} \mathrm{PD}$ activity in A. racemosus supplemented larvae of D. melanogaster. Ar I;dose-I treatment batch, Ar-II; dose-II treatment batch.

\section{4 $\mathrm{G}_{6} \mathrm{PD}$ assay}

It has been reported that the high activity of antioxidant enzymes can increase longevity [49]. Glucose -6-Phosphate dehydrogenase $\left(\mathrm{G}_{6} \mathrm{PD}\right)$ acts as a major factor in reducing NADPH level, upon which the entire antioxidant system relies. Many of the antioxidant enzymes are cofactor dependent like NADPH which can be generated through this $\mathrm{G}_{6} \mathrm{PD}$ enzyme. It enables the functioning of glutathione peroxidase [34]. $\mathrm{G}_{6} \mathrm{PD}$ is the principal source of NADPH, which serves as an antioxidant enzyme against ROS [50]. It catalyzes the oxidation of glucose-6-phosphate to 6 phospho gluconate and reduces NADP to NADPH in pentose phosphate pathway. Glutathione reductase requires NADPH to regenerate reduced glutathione [51]. Catalase converts hydrogen peroxide to less toxic compounds in the presence of NADPH [52, 53]. Hence the major antioxidant systems are dependent on the availability of NADPH that is principally produced by $G_{6} P D$. Adaptation to dietary sucrose in D. melanogaster increases activity in the enzyme $[54,55] . \mathrm{G}_{6} \mathrm{PD}$ activity has studied in different genetic stocks of $D$. melanogaster to correlate lifespan [56]. It has been reported that life span of $D$. melanogaster could be significantly extended by over expression of $\mathrm{G}_{6} \mathrm{PD}$ [57]. In the present analysis, $\mathrm{G}_{6} \mathrm{PD}$ activity was measured in the extract fed male and female of larvae, 30 and 45 days aged flies. The result on $\mathrm{G}_{6} \mathrm{PD}$ activity in extract supplemented larvae of $D$. melanogaster was compiled in Fig.3 The data reveals that the both the sexes of extract fed larvae showed a significantly increased enzyme activity when compared to control group. The activity in the larval stage of both doses of A. racemosus supplemented group was increased by 1.5 folds when compared to control group. The enzyme activity was also studied in both the sex of 30 and 45 days aged adult extract supplemented flies in stress and non stress conditions (Fig.4.)

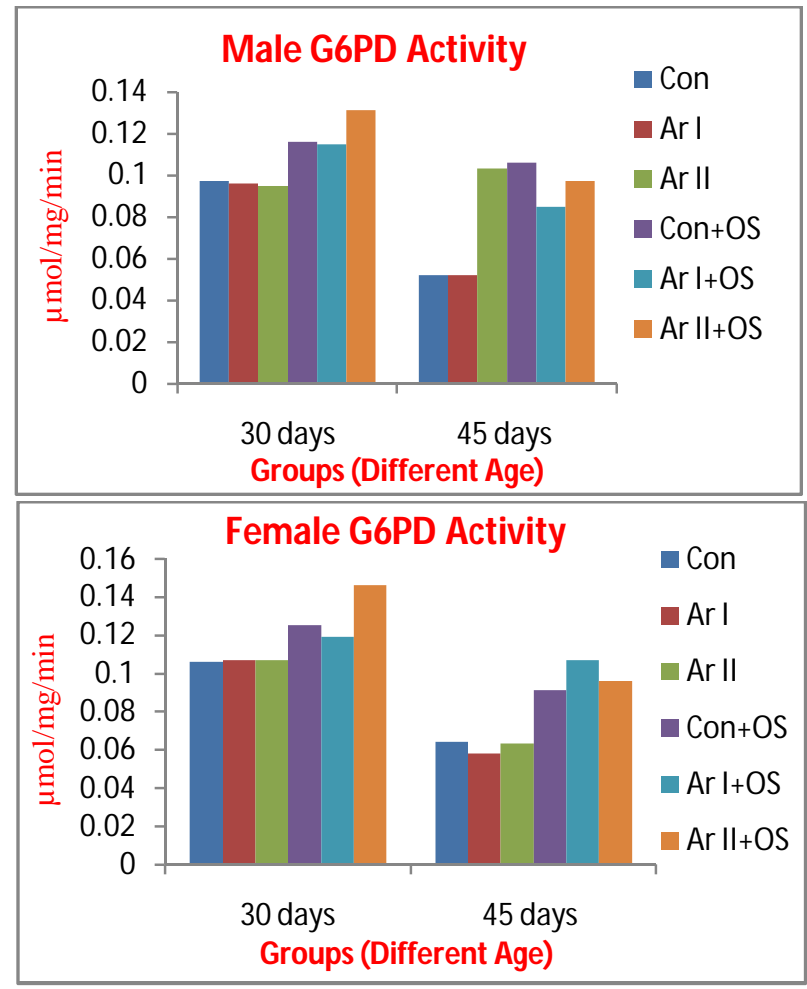

Fig. $4 \mathrm{G}_{6} \mathrm{PD}$ activity in $A$. racemosus supplemented flies of D.melanogaster. Ar I;dose-I treatment batch, Ar-II; dose-II treatment batch. 
The data shows that the activity was increased in case of 30 days aged flies in all the analyzed groups and declined in 45 days aged flies. The enzyme activity was remained same in both the sex of 30 days extract supplemented old flies as control flies. However, dose-II treated 45 days aged flies had significantly more enzyme activity when compared to control flies. Under stress condition, dose-II of 30days OS treated male and female flies had significantly more enzyme activity when compared to control flies. The over expression of $\mathrm{G}_{6} \mathrm{PD}$ in $D$. melanogaster increases the ability to synthesize NADPH which would enhance resistance to oxidative stress and extend the life span. [57]. In the present study also we have found similar such findings. Larval feeding rate decides the fitness of the fly [58]. The overexpression of $\mathrm{G}_{6} \mathrm{PD}$ was found in the larval stage of extract supplemented group, which could synthesize NADPH and enhance resistance to oxidative stress as well extend the life span.

In conclusion, the present investigation justifies that the ethanolic extract of $A$. racemosus is a rich source of antioxidant compounds. It extends the life span of $D$. melanogaster in both stress and non-stress conditions. The antioxidant property of $A$. racemosus increases the $\mathrm{G}_{6} \mathrm{PD}$ activity in larval stages, thereby increasing the lifespan of flies.

\section{Acknowledgements}

Authors thank the University Grants Commission (UGC) New Delhi for providing the financial assistance to carry out this research work.

\section{REFERENCES}

1. Muller F.L, Lustgarten M.S, Jang Y, Richardson A, Van Remmen.H. Trends in oxidative aging theories. Free RadicBiol Med. 2007; 43:477-503.

2. Perez V.I, Bokov A, Remmen H.V, Mele J, Ran Q, Ikeno Y, Richardson A. Is the oxidative stress theory of aging dead? Biochem Biophys Acta. 2009; 1790:1005-1014.

3. Harshman L.G. Genetic research on aging and longevity of Drosophila melanogaster. Population and Development Review. 2003; 29S: 99-126.

4. Strickberger M.W. Experiments in Genetics with Drosophila. John Wiley and Sons, Inc. 1962. New York.

5. Bourg, E.L. Oxidative stress, aging and longevity in drosophila melanogaster. FEBS Letters. 2011; 498: 183-186.

6. Parisa H, Nargues, Sanaz, V.G, Azadeh M, Gholamreza D, Mohammad A. In vivo antioxidant potential of Teucriumpolium, as compared to a-tocopherol. Acta Pharm. 2007; 57:123-129.

7. Jafari M, Zarban A, Pham S, Wang T. Rosa damascene Decreased Mortality in Adult Drosophila. Journal Of Medicinal Food. 2008; 11 : 9-13.

8. Cheng P, Zuo Y, Kwan K M, Liang Y, Ma K.Y, Chan HYE, Huang $\mathrm{Y}, \mathrm{Yu}$ H, Chen Z. Blueberry extract prolongs life span of Drosophila melanogaster. Experimental Gerentology. 2012; 47: 170-178.

9. Altun D, Ayar A, Uysal H, Kara AA, Unal EL. Extended longevity of Drosophila melanogaster by water and ethanol extracts of Stachyslavandulifolia. Pharm Biol. 2010; 48:1291-1296.

10. Chandrashekara K.T, Shakarad.M.N. Aloe veraorresveratrol supplementation in larval diet delaysadult aging in the fruit fly, Drosophila melanogaster. J Gerontol A BiolSci Med Sci. 2011; 66: 965-971.

11. Lee K.S, Lee B.S, Semnani S, Avanesian A, Um C.Y, Jeon H.J, Seong K.M, Yu K, Min K.J, Jafari M. Curcuminextends life span, improves health span, and modulates the expression of age(associated aging genes in Drosophila melanogaster. Rejuvenation Res. 2010; 13:561-570.

12. Pant D, Mansi Dave C, Anand K,Tiwari. Wheatgrass (Triticumaestivum L.) Supplementation Promotes Longevity in Drosophila melanogaster. Annals of plant sciences. 2013; 02:49-54.

13. Peng C, Zuo Y, Kwan K.M, Liang Y, Ma K.Y, Chan H.Y,Huang Y, $\mathrm{Yu}$ H, Chen Z.Y. Blueberry extract prolongs life span of Drosophila melanogaster. Exp Gerontol. 2012; 47:170-178.

14. Sujata, Mohanty, Rawal S, Singh P, Gupta A. Curcumin longa and Emblica officinalis increase lifespan in Drosophila melanogaster. DrosInfServ. 2011; 94: 122-125.

15. Bahadorani S, Hilliker A.J. Cocoa confers life span extension in Drosophila melanogaster. Nutrition Research. 2008; 28: 377-382.

16. Rege N.N, Thatte U.M, Dahanukar S.A. Adaptogenic properties of six rasayana herbs used in Ayurvedic medicine. Phytother Res. 1999; 13:275-91.

17. Pandey S.K, Sahay A, Pandey R.S, Tripathi Y.B. Effect of Asparagus racemosus rhizome (Shatavari) on mammary gland and genital organs of pregnant rat. Phytotherapy Research. 2005; 19:721724.

18. Sharma P.V, Charaka. S. Chaukhambhaorientalis. Varanasi India. 2001; 7-14.

19. Hossain M.I, Sharmin F.A, Akhter S, Bhuiyan M.A, Shahriar M. Investigation of Current cytotoxicity and in-vitro antioxidant activity of Asparagus racemosus root extract. International Pharmaceutical Journal. 2012; 1:250-257.

20. Kamat, J.P, Boloor K.K, Devasagayam T.P Venkata-chalam S.R. Antioxidant properties of Asparagus racemosus against damage induced by gamma-radiation in rat liver mitochondria. Journal Ethnopharmacology. 2000; 71: 425-435.

21. Dohare S, Shuaib M, Naquvi K.J. In-vitro antioxidant activity of Asparagus racemosus roots. IJBR. 2011; 24:228-235.

22. Chan EWC, Lim YY, Omar M. Antioxidant and antibacterial activity of leaves of Etlingera species (Zingiberaceae) in peninsular Malaysia. Food chemistry. 2007; 104: 1586 -1593.

23. Yildirim A, Mavi A, Kara A.A. Determination of Antioxidant and Antimicrobial Activities of Rumexcrispus L.Extracts. Journal of Agricultural and Food Chemistry. 2001; 49:4083-4089.

24. Demiray S, Pintado M.E, Castro PML. Evaluation of Phenolic Profiles and Antioxidant activities of Turkish Medicinal Plants: Tilia Argentea, Crataegi Folium Leaves and Polygonum Bistorta Roots. World Academy of Science, Engineering and Technology. 2009; $54: 312-317$.

25. Wang S.Y, Jiao H. Correlation of antioxidant capacities to oxygen radical scavenging enzyme activities in blackberry. Journal of Agricultural and Food Chemistry. 2000; 48:5672-5676.

26. Makkar, H.P.S, Dawra R.K, Singh. B. Determination of both tannin and protein in a tannin- protein complex. J AgricFoodChem. 1998; 523-525.

27. Yoon J.S, Gagen K.P, Zhu D. Longevity of 68 Species of Drosophila. The Ohio Journal of Science.1990; 90:16-32.

28. Prasad S.N, Muralidhara. Evidence of acrylamide induced oxidative stress and neurotoxicity in Drosophila melanogaster- its amelioration with spice active enrichment: relevance to neuropathy. Neurotoxicology. 2012; 33:1254-64.

29. Kumar S, Thomas A, Pillai M.K.K. Involvement of monooxygenases as a major mechanism of deltamethrin resistance in larvae of three species of mosquitoes. Indian J ExpBiol. 1991; 29: 379-84.

30. Meydani. M. Nutrition interventions in aging and age-associated diseases. Ann NY Acad Sci. 2001; 928:226-35.

31. Gupta A.K, Tandon N. Reviews on Indian Medicinal Plants.Vol. 3. New Delhi: Indian Council of Medical Research, 2004.

32. Bao, Y., Fenwick, R.G. Phytochemicals in Health and Disease. Marcel Dekker Inc., Basel, New York, pp. 2004; 331-342.

33. Joseph JA, Shukitt-Hale B, Lau FC. Fruit polyphenols and their effects on neuronal signaling and behavior in senescence. Ann N Y AcadSci. 2007; 1100:470-485. 
34. Liu R.H. Potential synergy of phytochemicals in cancer prevention: mechanism of action. J Nutr. 2004; 134:3479S-3485S.

35. Shahidi F, Janitha P.K, Wanasundara P.D. Phenolic antioxidants. Critical Reviews of Food Science and Nutrition. 1992; 32:67-103.

36. Havsteen B. Flavonoids a class of natural products of high pharmacological potency. Biochem Pharmacol. 1983; 30:1141-1148.

37. Lee K.P, Simpson S.J, Clissold F.J, Brooks R, Ballard JW, Taylor $\mathrm{PW}$, Soran N, Raubenheimer D. Lifespan and reproduction in Drosophila: New insights from nutritional geometry. ProcNatlAcadSci USA. 2008; 105:2498-2503.

38. Skorupa D.A, Dervisefendic A, Zwiener J, Pletcher S.D. Dietary composition specifies consumption, obesity, and lifespan in Drosophila melanogaster. Aging Cell. 2008; 7:478-490.

39. Papatheodorou I, Petrovs R. and Thornton J.M. Comparison of the mammalian insulin signalling pathway to invertebrates in the context of FOXO-mediated ageing. Bioinformatics Advance Access. 2014; $1-5$.

40. Brack C, Bechter-Thuring E, Labuhn M. N-acetylcysteine slows down aging increases the life span of Drosophila melanogaster. Cell MolLife Sci. 1997; 53: 960-966.

41. Driver C, Georgeou A. Variable effects of vitamin E on Drosophila longevity. Biogerontology. 2003; 4:91-95.

42. Sun X, Seeberger J, Alberico T, Wang C, Wheeler C.T, Schauss A.G, Zou S. Açai Palm Fruit (Euterpeoleracea Mart.) pulp improves survival of flies on a high fat diet. Exp Gerontol.2010; 45: 243-25

43. Hsin-Ping Liu, Rong-Fu Chang, Yih-Shyuan Wu,Wei-Yong Lin, and Fuu-Jen Tsai. The Yang-Tonifying Herbal Medicine Cynomorium songaricum Extends Lifespan and Delays Aging in Drosophila . Hindawi Publishing Corporation Evidence-Based Complementary and Alternative Medicine Volume 2012, Article ID 735481, pp 1-11

44. Aigaki T. and Ohba S. Effect of mating status on Drosophila virilis lifespan. Exp.Rerontol.1984; 19:267-278.

45. Cordts, R. and Partridge, L. Courtship reduces longevity of male Drosophila melanogaster. Animal Behavior. 1996; 52: 269-278.

46. Partridge.L, Ewing.E, Chandler. A. Male size and mating success in Drosophila melanogaster. The role of female and male behaviour. Anim Behav. 1987; 35:555-562.

47. Bahadorani S, Bahadorani P, Phillips JP, Hilliker AJ. The effects of vitamin supplementation on Drosophila life span under normoxia and under oxidative stress. J. Gerontol. A Biol. Sci. Med. Sci. 2008; 63, $35-42$.

48. Lobo V, Patil A, Phatak A, Chandra N. Free radicals, antioxidants and functional foods: Impact on human health. Pharmacogn Rev. 2010; 4:118-126.

49. Sohal R.S, Mockett R.J, Orr W.C. Mechanisms of aging: an appraisal of the oxidative stress hypothesis. Free Rad Biol Med. 2002; 33: $575-586$.
50. Leopold J.A, Zhang Y.Y, Scribner A.W, Stanton R.C, Loscalzo J. Glucose-6-Phosphate Dehydrogenase Overexpression Decreases Endothelial Cell OxidantStress and Increases Bioavailable Nitric Oxide. Arterioscler Thromb Vasc Biol. 2003; 23:411-417.

51. Meister. A. Glutathione metabolism and its selective modification. J BiolChem. 1988; 263:17205-17208.

52. Fridovich I. Superoxide anion radical (O2-), superoxide dismutases, and related matters. J. BiolChem .1997; 272: 18515-18517.

53. Kirkman H.N, Rolfo M, Ferraris A.M, Gaetani G.F. Mechanisms of protection of catalase by NADPH Kinetics and stoichiometry. Journal of Biological Chemistry. 1999; 274: 13908-13914.

54. Geer B.W, Lindel, D.L,Lindell O.M. Relationship of the oxidative pentose shunt pathway to lipid synthesis in Drosophila melanogaster Biochem Genetics. 1979; 17: 881-895.

55. Geer BW, Laurie-ahlberg.C.C. Genetic variation in dietary sucrose modulation of enzyme activities in Drosophila melanogaster. Genet. Res. Camb. 1984; 43: 307-321.

56. L S Luckinbill, V Riha, S Rhine and T A Grudzien. 1990 The role of glucose-6-phosphate dehydrogenase in the evolution of longevity in Drosophila melanogaster.

57. Legan S.K,Rebrin I, Mockett R.J, Radyuk S.N, Klichko V.I, Orr W.C, Sohal R.S. Over expression of Glucose-6-phosphate Dehydrogenase extends the life span of Drosophila melanogaster. Journal of Biological Chemistry.2008; 283:32492-32499.

58. Bochdanovits Z. and Jong G. D. Experimental evolution in drosophila melanogaster: interaction of Temperature and food quality selection regimes. Evolution. 2003; 57(8), pp. 1829-1836.

\section{How to cite this article:}

Kiran Kumar K.V., Prasanna K.S., Ashadevi J.S. Asparagus racemosus extract increases the life span in Drosophila melanogaster. J App Biol Biotech. 2015; 3 (04): 049-055. 